\title{
Friction stir welded and deep drawn multi-material tailor welded blanks
}

Florian Panzer, Matthias Schneider, Martin Werz and Stefan Weihe, Stuttgart, Germany

\section{Article Information}

\section{Correspondence Address}

Florian Panzer, M.Sc.

Materialprüfungsanstalt (MPA)

Universität Stuttgart

Abteilung Fügetechnik und Additive Fertigung

Referat Fügeverfahren

Pfaffenwaldring 32

D-70569 Stuttgart, Germany

E-mail: florian.panzer@mpa.uni-stuttgart.de

\section{Keywords}

Friction stir welding, multi-material tailor welded blanks
The ever increasing demand for more resource-efficient and safer vehicles in today's automotive industry makes lightweight construction techniques necessary. However, overcoming contradicting requirements arising from lightweight design and safety remains a challenging task. The extent to which lightweight measures can be applied in order to save fuel, heavily depends on the fact that rising safety requirements have to be met by increasing strength of parts. This contradicting demand for parts with high strength and low weight leads to the development of new production technologies. One example, regarding car body components, is the tailor welded blank (TWB) technology. In tailor welded blanks, materials and thicknesses are locally adapted to meet the needed strength and strain properties while keeping the weight as low as possible. While tailor welded blanks consisting of similar materials with different thicknesses are already used in vehicles, the use of TWBs with dissimilar materials, e.g. steel and aluminum, is still in development due to the problems in joining dissimilar materials. Especially when manufacturing parts made of TWBs through joining and subsequent deep drawing, the joint needs to have very good strength properties in order not to fail during forming. One way to overcome these joining difficulties is friction stir welding. In this paper, a methodology is presented to produce multi-material tailor welded blanks with varying thicknesses through friction stir welding (FSW) and deep drawing in a subsequent step. A newly developed FSW joint configuration is used to weld steel sheets in $1 \mathrm{~mm}$ thickness to $2 \mathrm{~mm}$ thick aluminum sheets. A welding parameter study is conducted to investigate the influence of the process parameters on the joint quality. Tensile and Nakajima tests show that the joint strength, obtained with optimal process parameters, exceeds the strength of the steel base material. Thus, failure occurs in the steel, whereas the joint remains intact. The friction stir welded blanks were furthermore deep drawn. Two different tool approaches were tested to compensate the different sheet thicknesses during the forming process. Using the more suitable approach, blanks were deep drawn with three different punch geometries to show the potential of friction stir welding for the manufacturing of multi-material tailor welded blanks.
The ever-increasing trend of producing resource-efficient vehicles, which meet the safety requirements, leads to the need of new technologies. As a result, the demand for light-weight and high-strength structures in automotive applications is steadily growing. In order to reduce the weight of the car body, tailor welded blanks are used, consisting of sheets of different materials and thicknesses. The basic idea of the tailor welded blank technology is to locally adapt material properties to the local 
strength and stiffness demands of complex parts and components.

The first challenge in producing tailor welded blanks consisting of different materials is the joining technology. Friction stir welding (FSW) is a solid state joining process in which the materials are joined without reaching their respective melting temperature. This circumstance not only allows the joining of similar materials, but also of different materials like aluminum and steel. Invented in 1991 by The Welding Institute [1, 2], this technology has found many fields of application throughout the last years. In FSW, a rotating tool is pressed into the gap between two parts. The friction between tool and parts produces heat, which leads to plasticizing of the material. The tool is then moved along the joint line. The combination of translation and rotation of the tool transports the material behind the tool, thus creating the joint as shown in Figure 1.

The most important process parameters of friction stir welding are the rotational speed, the feed speed, the axial force and

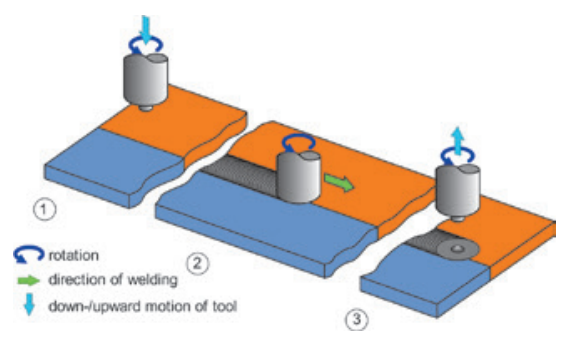

Figure 1: Schematic of friction stir welding

(a)

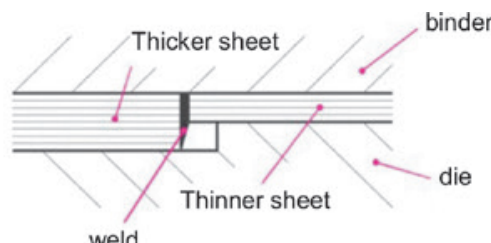

(b)

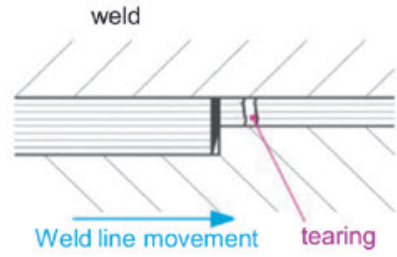

(c)

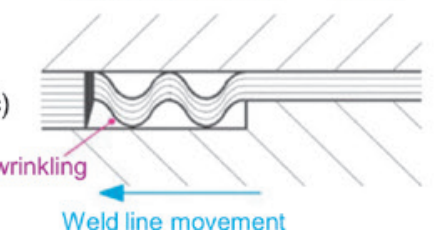

Figure 2: Typical failure types of deep drawing of tailor welded blanks due to weld line movement, a) initial position, b) tearing and c) wrinkling (based on [14, 15]) the tool tilt angle. When joining similar materials, the welding tool is placed in the middle of the joint line. However, when joining dissimilar materials, like aluminum and steel, the welding tool is moved almost exclusively in the softer material. This is necessary to reduce tool wear as well as to reduce the creation of brittle intermetallic compounds.

In this paper, tailor welded blanks consisting of aluminum and steel sheets with different thicknesses are manufactured including the production processes of friction stir welding and deep drawing of the joined sheets. A newly developed combined butt- and overlap-FSW-joint [3] is used to weld sheets of aluminum and steel of different thicknesses together. Zinccoated DX54D+ZM steel sheets having a thickness of $1 \mathrm{~mm}$ are joined with $2 \mathrm{~mm}$ thick AC600 as well as Al 6111 aluminum sheets. A parameter study shows the influence of welding parameters on the joint properties. The welded sheets are afterwards tensile and Nakajima tested as well as deep drawn to show the potential of the newly developed joining technology for the production of tailor welded blanks.

\section{Literature review}

In the following, a short overview is given of current standards of aluminum steel friction stir welding as well as forming of dissimilar tailor welded blanks.

FSW of aluminum and steel. Elrefaey et al. [4] friction stir welded commercially pure A1100H24 aluminum with low carbon zinc-coated steel in overlap configuration. Welds with the tool tip slightly penetrating the steel surface showed the highest fracture loads. It was furthermore concluded that the zinc coating has a positive influence on the strength of aluminumsteel-FSW-joints. Watanabe et al. [5] friction stir welded Al 5083 aluminum to a mild steel in butt configuration. The joints reached a maximum tensile strength of up to $86 \%$ of the aluminum base material. The best results were also achieved in welds where the tool penetrated the steel slightly. The offset was defined as a measure of how much the tool penetrates the steel. An offset of zero means that the pin is aligned with the steel, a positive offset indicates that the pin penetrates the steel and a negative offset means that the tool pin has some distance from the steel. The offset presents an additional parameter in FSW. Analyses of the joints lead to the assumption that regions with intermetallic com- pounds are fracture paths. Göttman et al. [6] friction stir welded AA 6016-T4 aluminum with DC04 steel in butt joint configuration. The best joints showed an ultimate tensile strength of $85 \%$ of the aluminum base material and failed in the thermomechanically affected zone of the aluminum. Further examples of aluminum-steel-FSW-joints with a great variety of different steel and aluminum alloys are summarized by Hussein et al [7]. As described in the works before, overlap and butt joints are used to weld steel and aluminum together. In the reviewed works, the feed speed does not exceed $480 \mathrm{~mm} /$ min, most authors used significantly lower feed speeds.

Forming of tailor welded blanks. The range of benefits of tailor welded blanks include cost reduction by requiring less forming dies as well as weight reduction through the possibility to use materials with different blank thicknesses. This, however, is contrasted by the major drawback that forming these TWBs is challenging. Difficulties in forming tailor welded blanks result from the use of materials with different properties and thicknesses. Here, major efforts have to be undertaken in order to ensure a successful process. Previous studies conducted by different researchers [8-10] report that formability and fracture mechanisms of parts made by friction stir welding are strongly influenced by the amount of mismatch in mechanical properties of the weld and base materials.

Furthermore, not only the weld properties have a significant influence on the forming behavior, but also the weld orientation [11-13]. For tailored blanks consisting of sheets with different thicknesses, a flow of material transversally to the weld line can lead to cracking or forming of wrinkles as shown in Figure 2.

In order to achieve optimal stiffness characteristics and crash behavior in car body construction, it is often necessary to design non-linear and non-matched weld lines. The weaker material in the weld connection tends to flow earlier, compared to the stronger material which leads to a movement of the weld line towards the stronger material.

The design guidelines for tailor welded blanks are as follows: The weld line should be placed in a way that the strain direction is longitudinal to the weld line. Furthermore, the weld line should be located in low-stretch areas. Taking both these guidelines into account, the weld line movement can be reduced and, thus, the formability of 
a)

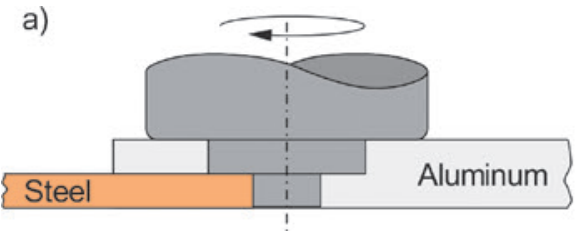

b)

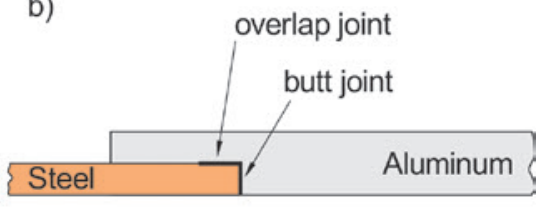

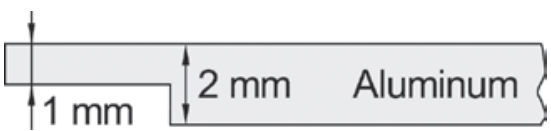

Figure 4: Preparation of aluminum sheets for welding

Figure 3: Combined butt and overlap joint

\begin{tabular}{|c|c|c|c|}
\hline & $\begin{array}{c}\text { Yield strength } \\
\mathrm{R}_{\mathrm{p} 0,2}(\mathrm{MPa})\end{array}$ & $\begin{array}{c}\text { Ultimate tensile strength } \mathrm{R}_{\mathrm{m}} \\
(\mathrm{MPa})\end{array}$ & $\begin{array}{c}\text { Total strain at maximum } \\
\text { load } \mathrm{A}_{\mathrm{gt}}(\%)\end{array}$ \\
\hline $\mathrm{DX} 54 \mathrm{D}+\mathrm{ZM}$ & 151 & 289 & 39 \\
\hline $\mathrm{AC}-600$ & 170 & 270 & 21 \\
\hline $\mathrm{Al} 6111 \mathrm{~T} 4$ & 161 & 274 & 18 \\
\hline
\end{tabular}

Table 1: Mechanical properties of DX54D+ZM, AC-600 and Al 6111 T4

the tailored blank can be increased [14]. In the past, additional, different methods have been developed in order to reduce or fully avoid weld line movement. One of these inventions is described in US-patent No. 5,941,110 [16]. Individual segments are integrated in the die and the punch and are used to clamp the weld line separately before the actual forming operation starts. With this technique, adaptive control of the relative movement of the punch can be achieved. Another method is to use a segmented blank holder, which, in literature, is often referred to as a flexible binder. The segmented blank holder is able to accomplish control of one segment while not being significantly influenced by the variation and distribution of other segments, thus enabling a controlled flange draw-in during the deep drawing process.

The forming behavior of tailored blanks can also be improved by homogenizing strain and thickness during the forming process. In Mennecart et al. [17], a concept to form tailored blanks of dissimilar strengths using tailored dies made of two different materials is presented. By means of this method, improved blank thickness distribution can be achieved compared to the use of a conventional die consisting of only one material.

In order to design a tailor welded blank in an ideal way, knowledge about the forming behavior and forming limits of the TWBs is necessary. A major limiting factor of formability is the weld seam. There are different

\begin{tabular}{|c|c|c|c|c|c|}
\hline $\mathrm{C}$ & $\mathrm{Si}$ & $\mathrm{Mn}$ & $\mathrm{P}$ & $\mathrm{S}$ & $\mathrm{Ti}$ \\
\hline 0.12 & 0.50 & 0.60 & 0.10 & 0.045 & 0.30 \\
\hline
\end{tabular}

Table 2: Chemical composition of DX54D+ZM (amount in wt.\%) [22] methods suitable for characterizing the formability of tailor welded blanks, such as tension tests, Erichsen cupping tests or the cylindrical cup deep drawing test. Previous studies show that the strength of the friction stir welded joint is comparable with that of the weaker material. However, in none of the experimental tests, limiting drawing ratios of the base material were achieved. This is mainly due to the weld line movement which significantly diminishes the deep drawability $[18,19]$.

\section{Experimental procedures}

Welding of tailor welded blanks. The joint FSW-configuration that was newly developed [20], is schematically shown in Figure 3. The joint consists of a combination of butt and overlap configuration (see Figure $3 \mathrm{~b}$ ). A specially designed tool with a stepped pin (see Figure 3a) is used to weld aluminum and steel sheets of different thicknesses together. The lower part of the pin creates the butt joint, while the upper part creates the overlap joint. As described before, the tool has an offset into the steel. Benefits of the combined butt and overlap joint are very good static and fatigue strengths as well as low tool wear. Drawbacks are increased tolerance requirements. First investigations using HC340LA steel and EN AW 6016 T4 aluminum [3] showed that an ultimate tensile strength of up to $89.9 \%$ compared to the aluminum base material can be achieved. Further- more, the joints showed excellent fatigue strengths.

In this work, different materials are welded. The zinc-coated steel sheet material DX54D+ZM is used due to its very good forming characteristics. The mechanical properties and chemical composition of the steel can be found in Tables 1 and 2. For aluminum, as the other join partner, the alloy AC-600 as well as the alloy Al 6111, both in $\mathrm{T} 4$ temper, are used. AC-600 (Al 6451) is an alloy developed by Novelis [21], which is specially designed for automotive applications and combines high strength with good forming properties. $\mathrm{Al} 6111$ is an alloy which is also mostly used in automotive applications, typically for outer panels of car bodies. As shown in Table 1, the two aluminum alloys have very similar mechanical properties. The main difference in chemical composition is the amount of copper, as listed in Table 3. The sheet thickness of the steel was chosen to be $1.0 \mathrm{~mm}$, the sheet thickness of the aluminum alloys to be $2.0 \mathrm{~mm}$. The chosen materials are a combination that could be used in automotive body applications.

The aluminum sheets were milled on one edge in order to reduce the thickness locally to $1 \mathrm{~mm}$, as shown in Figure 4. With this preparation, the combined butt and overlap configuration can be welded more easily than other versions of this joint configuration.

Welding was performed on a dedicated FSW machine by ESAB, as shown in Figure 5. The machine is equipped with one linear axis and can provide up to $25 \mathrm{kN}$ of axial force and a feed speed of up to $4000 \mathrm{~mm} \times \mathrm{min}^{-1}$.

A specially designed device using two micrometers, as shown in Figure 6, was used in order to conveniently adjust the offset. The two micrometers allow to position the steel sheet precisely with regard to the tool position in lateral direction. After the

\begin{tabular}{|c|c|c|c|c|c|c|c|c|}
\hline & Si & Fe & Cu & Mn & Mg & Cr & Zn & Ti \\
\hline AC-600 & $0.6-1.0$ & 0.4 & 0.4 & $0.05-0.40$ & $0.4-0.8$ & 0.1 & 0.15 & - \\
\hline Al 6111 & $0.6-1.1$ & 0.4 & $0.5-0.9$ & $0.10-0.45$ & $0.5-1.0$ & 0.1 & 0.15 & 0.1 \\
\hline
\end{tabular}

Table 3: Chemical composition of AC-600 and Al 6111 (amount in wt.\%) [23] 


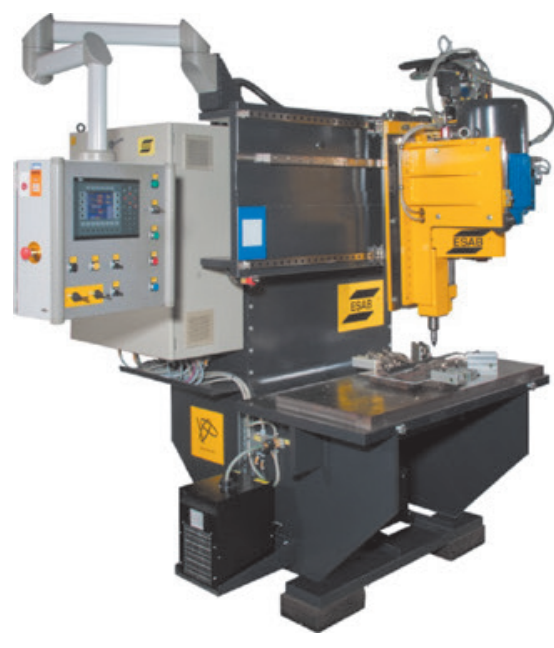

Figure 5: ESAB FSW machine

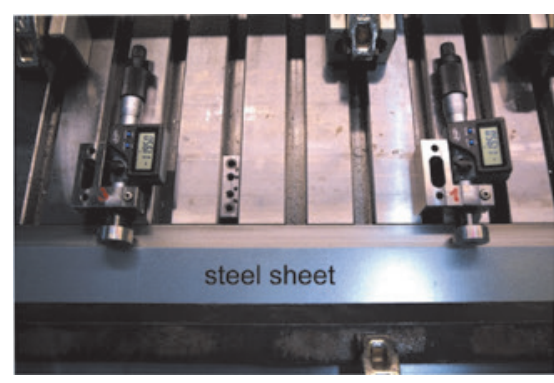

Figure 6: Offset adjustment

steel sheets are clamped down, the micrometers are removed and the aluminum sheet is positioned by aligning the milled edge with the edge of the steel sheet. Both sheets were cleaned with ethanol before welding.

The optimal process parameters for friction stir welding of the selected material combinations are listed in Table 4. These parameters were used to fabricate all sheets that were either tensile tested, deep drawn or Nakajima tested in a subsequent step. The used feed speed is higher than current standards found in literature in order to meet industrial minimum require-
Figure 7: Forming Limit Diagram with the different strain conditions (based on [25])

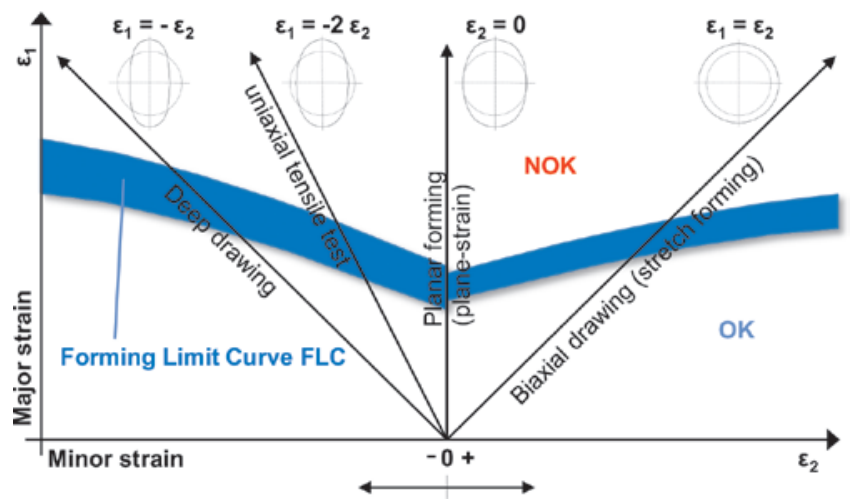

\begin{tabular}{|c|c|c|c|c|c|}
\hline & $\begin{array}{c}\text { Rot. speed } \\
\left(1 \times \text { min }^{-1}\right)\end{array}$ & $\begin{array}{c}\text { Axial force } \\
(\mathrm{N})\end{array}$ & $\begin{array}{c}\text { Feed speed } \\
\left(\mathrm{mm}^{\circ} \text { min }^{-1}\right)\end{array}$ & $\begin{array}{c}\text { Tilt angle } \\
\left({ }^{\circ}\right)\end{array}$ & $\begin{array}{c}\text { Offset } \\
(\mathrm{mm})\end{array}$ \\
\hline DX54D+ZM/ AC-600 & 1300 & 11000 & 1000 & 3 & 0.2 \\
\hline DX54D+ZM/ Al 6111 & 1100 & 11000 & 1000 & 3.5 & 0.3 \\
\hline
\end{tabular}

Table 4: Optimal FSW parameters

ments. The influence of welding parameters on the properties of the joint is analyzed in a parameter study with one parameter varying at a time.

Tensile testing. For tensile testing, a Zwick $10 \mathrm{kN}$ electromechanical universal testing machine was used in combination with a mechanical extensometer. The measuring length of the extensometer was chosen to be $50 \mathrm{~mm}$ with regard to ISO 6892 [24]. The FSW seam was positioned in the middle of the measuring length and oriented in rolling direction of the joint partners.

Nakajima testing. The Nakajima test is one of the most commonly used methods to evaluate the formability of sheet metal materials under different strain conditions, and to determine forming limit curves (FLC) of the respective materials (see Figure 7). The shape and position of the FLC in the Forming Limit Diagram (FLD) depend on different factors such as material thickness, material strength and deformation history. In order to obtain a complete form- ing limit curve, six different specimens with different widths, as shown in Figure 8 , were tested in order to achieve different strain conditions.

The difference in thickness between the steel and aluminum sheets has to be compensated. Otherwise, wrinkling of the thinner material, tearing near the weld region and weld line movement, which will deteriorate the formability of the welded to compensate the difference in thickness. In this study, a shim was inserted below the thinner blank. This is possible because the blank holder pressure is high enough to avoid draw-in of the thinner material during the forming process, which is a requirement for valid Nakajima tests. With the shim, the specimen is sufficiently clamped between blank holder and die.

Tests to determine forming limit curves of the base materials and the tailor welded blanks were performed according to DIN EN ISO 12004-2 [27]. The technical equipment used is depicted in Figure 9. blanks, will occur. There are several ways

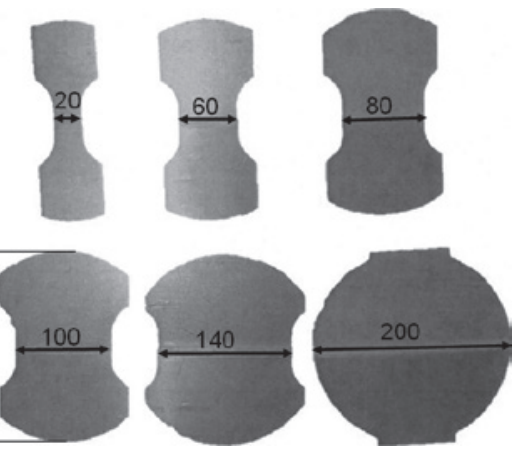

Figure 8: Geometry (in mm) of the Nakajima specimens (based on [26])

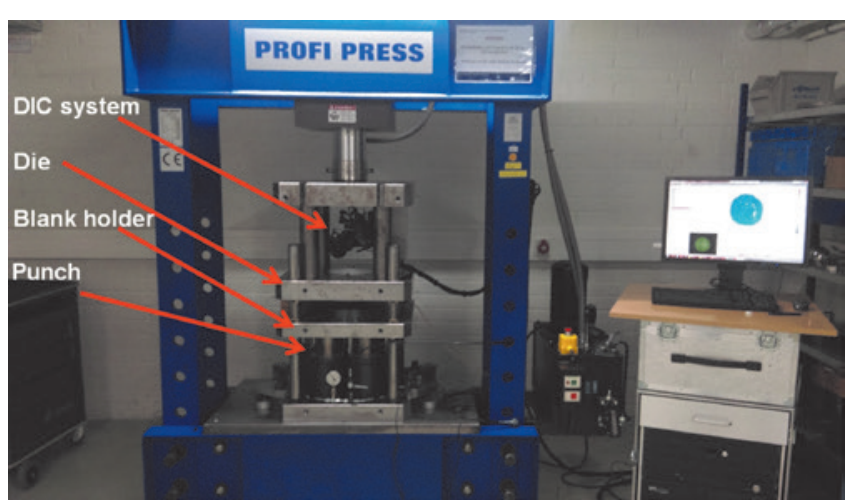


The Profi Press 160T type can provide a force of up to 160 tons. A maximum drawing speed of up to $2.5 \mathrm{~mm} \times \mathrm{s}^{-1}$ can be performed. Each specimen is formed until failure occurs. The measuring system used in order to determine the deformation behavior of all specimens is the GOM Aramis metrology system. With this measuring device, it is possible to measure strains at the surface of a specimen without any contact during the whole deformation process.

Deep drawing. In order to evaluate the feasibility of the friction stir welded blanks as tailor welded blanks, the forming behavior was examined by using different geometries. Since the tailor welded blanks consist of sheets of different thicknesses, a way had to be found to compensate for this difference in thickness in the deep drawing process and to guarantee a uniform blank holder pressure. These examinations were done using a cylindrical geometry of the TBWs with a diameter of $100 \mathrm{~mm}$. In the first approach, an adaption of the upper tool part was made. As shown in Figure $10 \mathrm{a}$, the draw ring was divided into two parts. The draw ring was stepped in order to compensate the difference in thickness of the TWBs. Additionally, a gap was included between the two halves to provide a clearance for the weld line to be able to move freely in the flange area during the forming process. The deep drawing experiments, however, showed that this gap was designed too large. As a consequence, parts with wrinkles were produced due to the lack of binder force in the gap zone. For this reason, a conventional one-piece draw ring without gap or step was used in the second approach (see Figure 10b). In doing so, optimal surface pressure on the flange of the component, even in the weld zone, can be achieved during deep drawing. In order to compensate the stepped tailor welded blank, an additional aluminum sheet with a thickness of $1.0 \mathrm{~mm}$ was placed on top of the steel part of the TWB. With this approach, the occurrence of wrinkles and weld line movement was reduced significantly.

Since the second approach allows for deep drawing without modifications of the tool, it was used to conduct experiments with two other punch geometries in addition to the circular cups. Experiments were done with rectangular cups and with a special geometry having a convex-concave shape. In both cases, tailor welded blanks were used, consisting of two aluminum sheets with one steel sheet in the middle.

\section{Results and discussion}

Welding parameter study. In order to examine the influence of welding parameters, a study with parameters, as listed in Table 5, was conducted. In addition to the rotational speed, axial force, feed speed and tilt angle, the resulting ultimate tensile strength of the respective joints is listed.

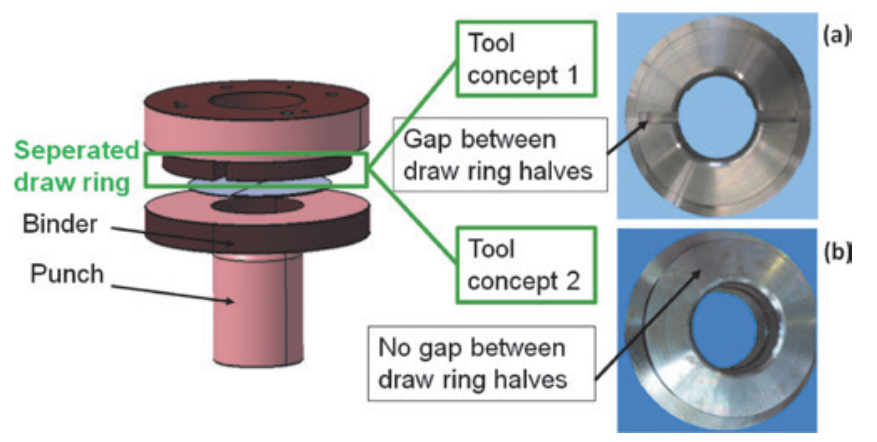

Figure 10: a) Tool concept 1 and $b$ ) tool concept 2 for deep drawing round cups from tailor welded blanks with a difference in sheet thickness (based on [26])

\section{Weld \#1}

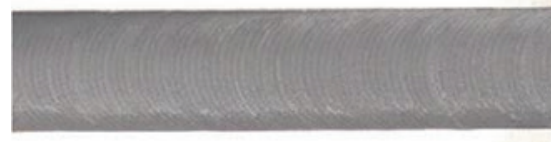

\section{Weld \#7}

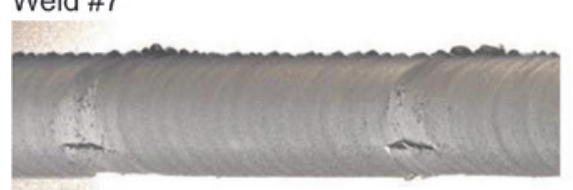

The strength is calculated with respect to the thickness of the aluminum sheet. Figure 11, furthermore, shows the surfaces of four selected friction stir welds. The starting point for the study were the optimal parameters as listed in Table 4.

As seen in Table 5, a change of welding parameters away from the optimum of weld \#1 in all cases results in a deteriora-
Figure 11: Surfaces of selected welds (DX54+ZM/Al 6111 T4)

\begin{tabular}{|c|c|c|c|c|c|c|}
\hline Weld \# & $\begin{array}{l}\text { Rot. speed } \\
\left(1 \times \min ^{-1}\right) \\
\end{array}$ & $\begin{array}{l}\text { Axial force } \\
(\mathrm{N})\end{array}$ & $\begin{array}{c}\text { Feed speed } \\
\left(\mathrm{mm} \times \mathrm{min}^{-1}\right)\end{array}$ & $\begin{array}{c}\text { Tilt angle } \\
\left({ }^{\circ}\right)\end{array}$ & $\begin{array}{l}\text { Offset } \\
(\mathrm{mm})\end{array}$ & $\begin{array}{c}\text { Ultimate tensile } \\
\text { strength } \mathrm{R}_{\mathrm{m}}(\mathrm{MPa})\end{array}$ \\
\hline 1 & 1100 & 11000 & 1000 & 3.5 & 0.3 & 153 - failure in steel \\
\hline 2 & 1400 & 11000 & 1000 & 3.5 & 0.3 & 125 \\
\hline 3 & 800 & 11000 & 1000 & 3.5 & 0.3 & 143 \\
\hline 4 & 1100 & 13000 & 1000 & 3.5 & 0.3 & 145 \\
\hline 5 & 1100 & 9000 & 1000 & 3.5 & 0.3 & 140 \\
\hline 6 & 1100 & 11000 & 2000 & 3.5 & 0.3 & insufficient \\
\hline 7 & 1100 & 15000 & 2000 & 3.5 & 0.3 & 141 \\
\hline 8 & 1100 & 11000 & 500 & 3.5 & 0.3 & insufficient \\
\hline 9 & 1100 & 8000 & 500 & 3.5 & 0.3 & 119 \\
\hline 10 & 1100 & 11000 & 1000 & 3.5 & 0.1 & 137 \\
\hline 11 & 1400 & 11000 & 1000 & 3.5 & 0.1 & 104 \\
\hline 12 & 1100 & 11000 & 1000 & 3.5 & 0.5 & 146 \\
\hline 13 & 1400 & 11000 & 1000 & 3.5 & 0.5 & 125 \\
\hline 14 & 1100 & 11000 & 1000 & 2.5 & 0.3 & 142 \\
\hline 15 & 1100 & 11000 & 1000 & 1 & 0.3 & 83 \\
\hline
\end{tabular}

Table 5: Welding parameter study with DX54+ZM/Al 6111 T4 (the values in bold show the varying welding parameters) 


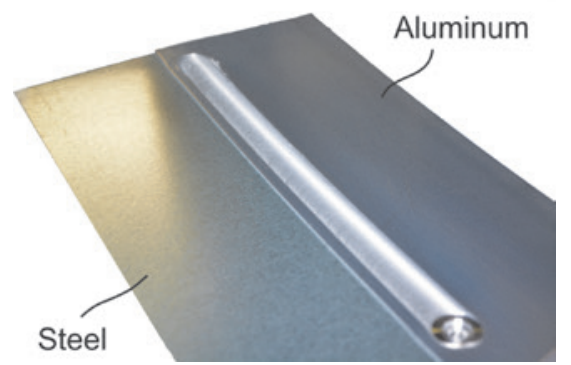

Figure 12: Tailor welded blank (DX54D+ZM/AC-600)

tion of weld strength. A higher rotational speed (weld \#2) leads to a higher heat input and therefore to the formation of brittle, strength-reducing intermetallic compounds. The reduction of rotational speed (weld \#3) reduces heat input which, in turn, leads to a reduced thermal-mechanical activation. The change of axial force (weld \#4 and \#5) changes the position of the tool. This, in turn, leads to disturbance of the welding process and weld formation. The same effect occurs when the feed speed is changed while keeping the other parameters constant (weld \#6). The higher reaction force from the welding process forces the tool in a position where the shoulder only has insufficient contact to the aluminum and no successful formation of the weld can take place, as seen in Figure 11. If the axial force is increased (weld \#7), weld formation is - at least partly - possible. Analogously, lower feed speed leads to incorrect tool position, which has to be adjusted by changing axial force (welds \#8 and \#9). A change of offset (welds \#10 to \#13) again leads to deteriorated joint strengths. This shows the need for exact adjustment of the offset (see Figure 6). A change of tool tilt angle without adaption of the other parameters, as already described, leads to a tool position that does not allow for successful joint formation. Figure 12 shows a tailor welded blank after welding with parameters as listed in Table 4 before tensile testing or deep drawing.

Tensile tests. The results of the tensile tests of the aluminum base material, steel base material and welded specimen can be seen in Figure 13. The stress of the welded specimen is calculated with respect to the thickness of the steel sheet.

The stress-strain-curve of the welded specimen shows the same ultimate tensile strength as the steel base material. This means that the line load the joint can bear is higher than the line load the steel base material can carry. The fracture strain of the FSW joints, however, is significantly lower than that of the base materials. This can partly be attributed to the strain hindrance that is caused by joining sheets of different thicknesses and materials.

As shown in Figure 14, failure in the welded specimen occurs in the steel base sheet, while the joint itself remains unaltered. Compared to the steel, the aluminum does not show large deformations. This fact can be attributed to the different sheet thicknesses. Although the tensile strength of the aluminum is lower, the higher thickness of the aluminum sheet leads to higher bearable loads than for the steel sheet. Only the steel showing large deformations contributes to the relatively low fracture strain of the FSW specimen in the tensile tests.

Nakajima testing. In the following section, the results of the Nakajima tests of the friction stir welded materials (DX54 in $1.0 \mathrm{~mm}$ and AC-600 in $2.0 \mathrm{~mm}$ ) are shown. In specimen geometries with a width of $20 \mathrm{~mm}$, the crack always occurred in the steel base material. For all other specimens with different widths, no uniform failure location could be found. The crack either occurred in the steel material or in the FSW seam. In Figure 15, major and minor strains in the base material DX54D+ZM (top) and in one specimen of the tailor welded blanks made of DX54D+ZM and AC-600 (bottom) are shown.

The different forming behaviors and different locations of the cracks can clearly be observed. The similar mechanical properties but different thicknesses of the steel and aluminum sheet (see Table 1) result in a larger deformation of the steel sheet. This inhomogeneous deformation results in a weld line movement in the direction of the aluminum sheet. For the steel base material, a symmetrical strain distribution with the major deformation zone in the center can be observed.

Figure 16 shows the forming limit curves obtained in the Nakajima tests of the base materials DX54D+ZM and AC-600, as well as of the tailor welded blank. The steel sheet shows the largest forming capacity, while the aluminum alloy shows a smaller formability with critical major strains in

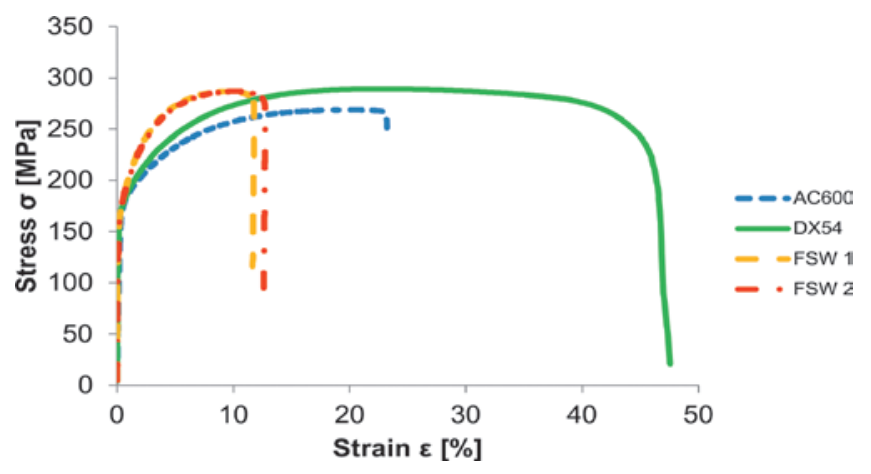

Figure 13: Tensile tests of base materials and FSW joints

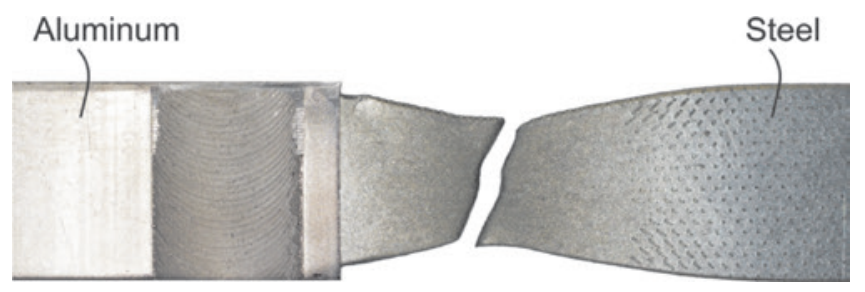

Figure 14: Tensile tested FSW specimen

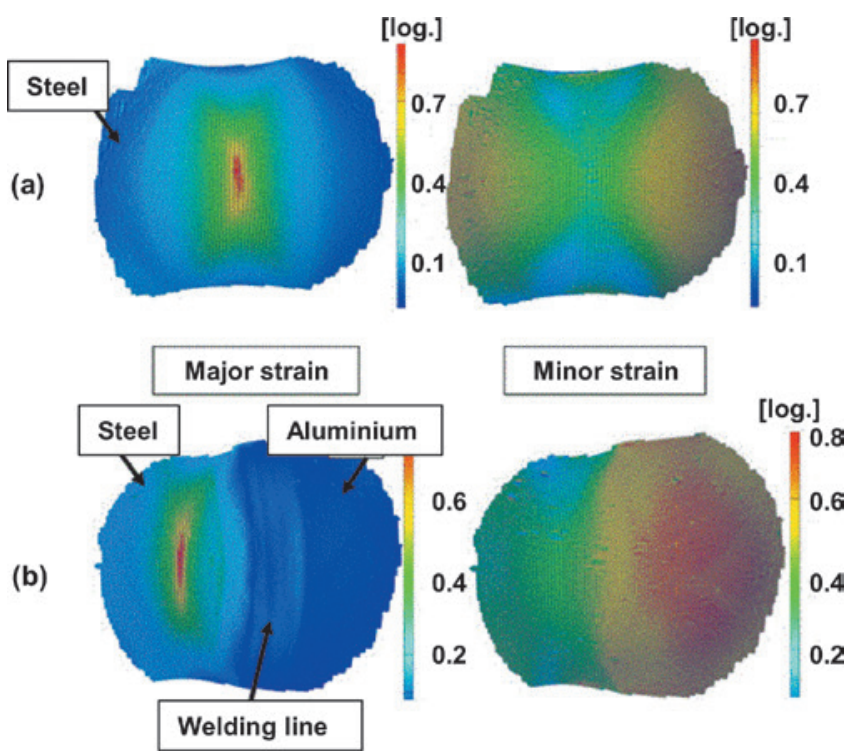

Figure 15: Major (left) and minor (right) strain distribution of a) the base material $D X 54 D+Z M$ and b) of the tailor welded blanks made of DX54D+ZM/AC-600 (based on [26]) 
the range of $0.28-0.45$. The tailor welded blank shows a maximum major strain, which is $20 \%$ smaller than that of the steel, but $32 \%$ higher than that of the aluminum base material. In the range of plane strain (minor strain $\approx 0$ ), however, the TWB shows only very limited formability.

Derivation of the FLC of tailor welded blanks using the experimental procedure according to DIN EN ISO 12004-2 must be seen critical if looking at the results, especially in the area of plane strain. No homogeneous, almost friction-less contact between TWB and die can be guaranteed due to the weld line, distortions of the sheets as well as the different thicknesses of the sheets. Additionally, failure of the specimen does not occur in the center, as shown in Figure 15. This leads to the conclusion that the determination of forming limit curves according to the DIN EN ISO 12004-2 standard might not be suitable for tailored blanks and further research needs to be carried out to identify appropriate test methodologies. The results obtained in this work are only of comparative nature.

Deep drawing. Figure 17 shows circular cups formed using the two different tool approaches, on the left side tool concept 1 , and on the right side tool concept 2. As can be seen, forming without failure of the weld is possible with both tool concepts. The gap between the draw ring halves of the first tool concept, however, leads to formation of wrinkles since no pressure is applied in this area on the flange of the cup. With the second tool approach, cups without wrinkle formation and only little weld line movement can be formed.

In Table 6, the achieved draw depths of the cups are listed. A draw depth of $30 \mathrm{~mm}$ was achieved with the aluminum alloy and the tailored blanks, while the steel base material shows a slightly higher draw depth of $32 \mathrm{~mm}$. In the case of the tailor welded blanks, no failure occurred in the weld, but rather in the area of the punch radius, i.e. in the aluminum base material at the bottom of the cup. In the case of the base materials, as expected, failure also occurred at the bottom of the cup.

Figure 18 shows two rectangular cups that were deep drawn with a punch having a length of $150 \mathrm{~mm}$ and a width of $100 \mathrm{~mm}$. The punch has a radius of $20 \mathrm{~mm}$ in the corners and $10 \mathrm{~mm}$ in all other areas. A blank holder force of $250 \mathrm{kN}$ was used and as for the circular cups and tool concept 2, an additional aluminum sheet was used to compensate the different sheet thick- nesses. Cups with two different weld orientations, i. e. $0^{\circ}$ and $90^{\circ}$, were formed.

The cups show a symmetrical deformation behavior, which can be attributed to the three-piece tailored blanks consisting of two aluminum sheets and one steel sheet. In the $0^{\circ}$-orientation, a draw depth of $33 \mathrm{~mm}$ was achieved while a draw depth of $22 \mathrm{~mm}$ was achieved in the $90^{\circ}$-orientation. This difference can be explained by the distance between the weld line and the corner of the punch. When the weld is positioned on the shorter edge of the punch, a higher lateral displacement of the weld occurs due to the higher tangential stresses in the area of the corner. With increasing draw depth, the lateral displacement of the weld increases and finally results in failure of the joint.

Figure 19 shows a tailor welded blank that was deep drawn using a punch with a more complex, convex-concave shape. Once again, a three-piece tailor welded blank, an additional aluminum sheet - to compensate the difference in thickness and a blank holder force of $250 \mathrm{kN}$ were used. As before, the two weld orientations $0^{\circ}$ and $90^{\circ}$ were tested.

With a weld orientation of $0^{\circ}$, successful forming of the tailor welded blanks with a draw depth of up to $44 \mathrm{~mm}$ was possible (see Figure 19). In this case, the weld is

\begin{tabular}{|l|c|c|c|}
\hline & DX54D+ZM & AC-600 & DX54D+ZM / AC-600 \\
\hline Drawing depth $(\mathrm{mm})$ & 32 & 30 & 30 \\
\hline
\end{tabular}

Table 6: Achieved drawing depths of circular cups

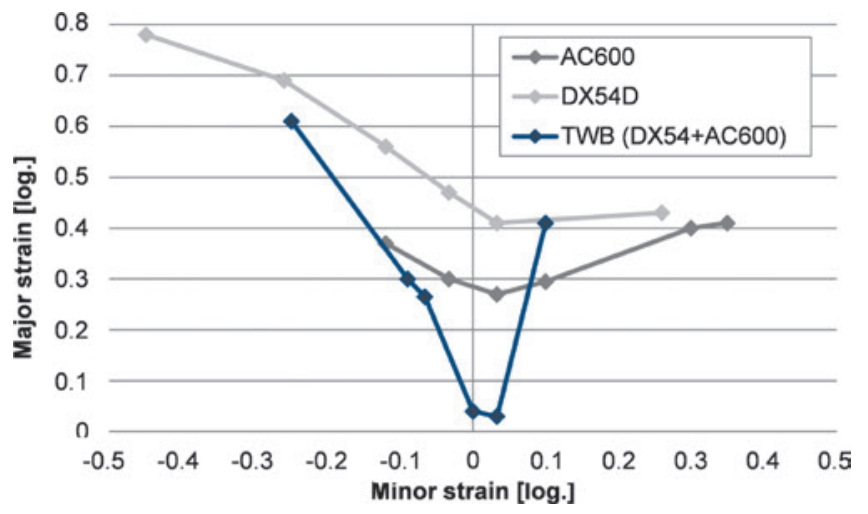

Figure 16: Forming limit curves (FLC) of the base materials and of the friction stir welded TWB made of DX54D+ZM $(1.0 \mathrm{~mm})$ and $A C-600$ (2.0 mm) (based on [26])
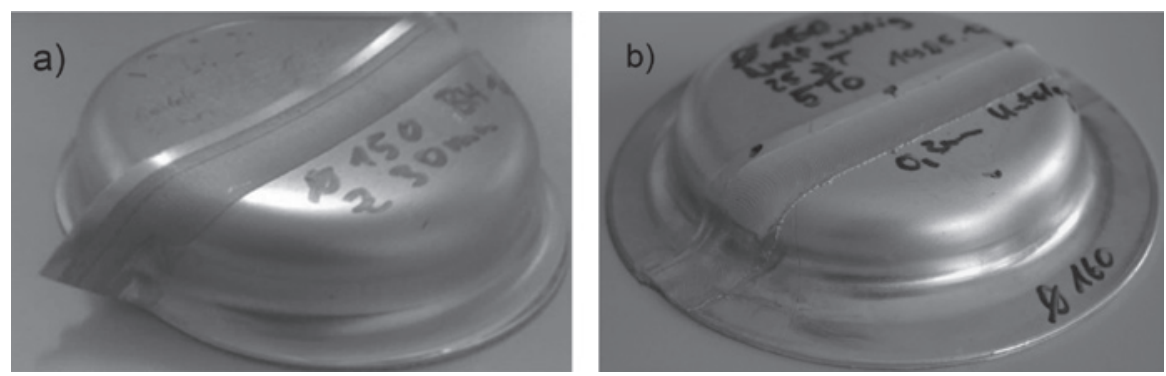

Figure 17: Deep drawn cups (DX54D+ZM/AC-600) manufactured with a) tool concept 1 and b) tool concept $2[26]$

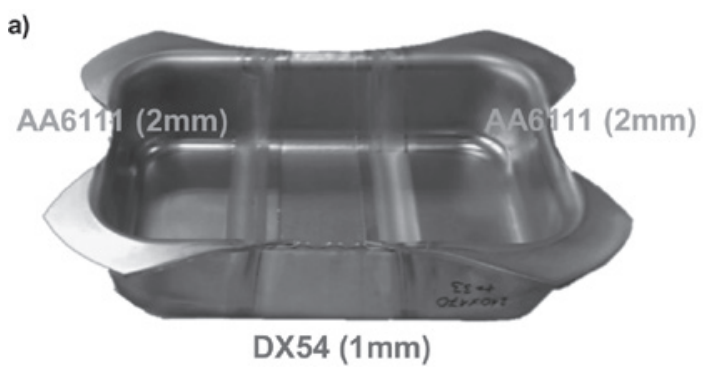

b)

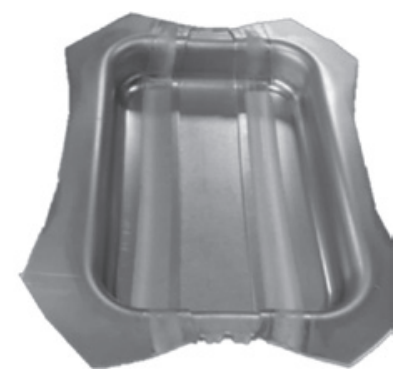

Figure 18: Rectangular cups drawn with tool concept 2 with a weld orientation of a) $0^{\circ}$ and b) $90^{\circ}$ [26] 


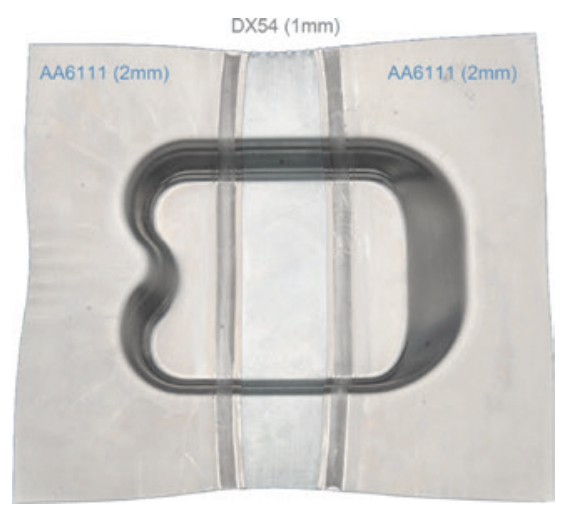

Figure 19: Tailor welded blank deep drawn with convex-concave punch

only subjected to tension and compression, and therefore no failure of the joint occurs. With an orientation of $90^{\circ}$, however, no tailor welded blanks could be successfully formed. In this case, the weld is subjected to a multiaxial stress state in the area of the convex-concave shape, which results in a higher load. In combination with the possibility that the tested blanks had variations in the strengths of the welds due to the experimental process setup, this lead to failure of the joints during deep drawing.

\section{Conclusions and outlook}

Tailor welded blanks consisting of steel and aluminum in different thicknesses were manufactured by friction stir welding and subsequent deep drawing. Using a newly developed FSW joint configuration, the mild steel DX54D+ZM with a thickness of $1 \mathrm{~mm}$ was welded to $2 \mathrm{~mm}$ thick aluminum AC600 and $\mathrm{Al} 6111$ sheets. A welding parameter study showed that changes of e.g. $27 \%$ of the rotational speed or $50 \%$ of the feed speed lead to joints with inferior qualities.

With the appropriate welding parameters, however, welds were produced with the joint strength exceeding the strength of the steel sheet, i.e. failure during tensile testing occurred in the steel base material. Nakajima testing also showed that failure in the base steel sheet and not in the weld itself is possible during the forming process. The Nakajima experiments additionally showed the need to develop a suited material characterizing procedure for tailor welded blanks consisting of sheets of different materials and thicknesses.

In order to show the suitability of the welding process to produce formed tailor welded blanks, the welded sheets were successfully deep drawn using three different punch geometries. Draw depths of up to
$44 \mathrm{~mm}$ were achieved. In order to compensate the difference in thickness of the sheets, an additional aluminum sheet was added on top of the thinner steel sheet as skimming. In doing so, no modification of the drawing tools is necessary. The deep drawing experiments furthermore showed that appropriate orientation of the weld line is crucial to produce blanks without failures.

This study is a first step to show the potential of friction stir welding to produce multi-material tailor welded blanks with different sheet thicknesses.

The relatively soft DX54D+ZM steel with good forming characteristics is used. In order to fully exploit the potential of the friction stir weld joint configuration, steels with higher strengths should be used. In order to achieve the necessary joint strengths for the forming of such material combinations, optimization of the welding process is necessary. One possible solution may be to use heat treatment after welding.

The approach to use an additional aluminum sheet to compensate the difference in the sheet thickness during the forming process has the drawback that one scrap part is produced during the forming of one part. While this is acceptable for experiments, an alternative solution has to be found for industrial implementation.

\section{Acknowledgements}

The authors would like to thank the "Ministerium für Wirtschaft, Arbeit und Wohnungsbau Baden-Württemberg” (Ministry of Economic Affairs, Labour and Housing Baden-Württemberg) for providing funding for the presented research work within the scope of the program "Technologischer Ressourcenschutz".

The authors would furthermore like to thank the Institute for Metal Forming Technology (IFU) of the University of Stuttgart for providing access to presses as well as for carrying out forming experiments.

\section{References}

1 W. Thomas, E. Nicholas, J. Needham, M. Murch, P. Templesmith, C. Dawes: Great Britain Patent G. B. Patent Application No. 9125978.8, 1991

2 C. Dawes, W. Thomas: Friction stir joining of aluminium alloys. TWI Bulletin 6 (1995), UK

3 M. Werz, M. Seidenfuß: High-strength friction stir welds for joining aluminum and steel with dissimilar sheet thicknesses, $11^{\text {th }}$ International Symposium on Friction Stir Welding, Cambridge, 2016

4 A. Elrefaey, M. Takahashi, K. Ikeuchi: Frictionstir-welded lap joint of aluminum to zinccoated steel, Quarterly Journal of the Japan
Welding Society 23 (2005), No. 2, pp. 186-193 DOI:10.2207/qjjws.23.186

5 T. Watanabe, H. Takayama, A. Yanagisawa: Joining of aluminum alloy to steel by friction stir welding, Journal of Materials Processing Technology 178 (2006) No. 1-3, pp. 342-349 DOI:10.1016/j.jmatprotec.2006.04.117

6 A. Göttmann, C. Mertin, L. Mosecker, A. Naumov, M. Bambach: Properties of friction stir welded blanks made from DC04 mild steel and aluminum AA6016, Advanced Materials Research 769 (2013), pp. 237-244 DOI:10.4028/www.scientific.net/AMR.769.237

7 S. A. Hussein, A. S. M. Tahir, A. B. Hadzley: Characteristics of aluminum-to-steel joint made by friction stir welding: A review, Materials Today Communications 5 (2015), pp. 32-49 DOI:10.1016/j.mtcomm.2015.09.004

8 M. Koçak: Structural integrity of welded structures: process-property-performance (3P) Relationship. 63 ${ }^{\text {rd }}$ Annual Assembly \& International Conference of the International Institute of Welding, 2010

9 T. Tanaka, T. Hirata, N. Shinomiya, N. Shirakawa: Analysis of material flow in the sheet forming of friction-stir welds on alloys of mild steel and aluminum, Journal of Materials Processing Technology 226 (2015), pp. $115-124$ DOI:10.1016/j.jmatprotec.2015.06.030

10 C. Leitao, B. Emilio, B. M. Chaparro, D. M. Rodrigues: Formability of similar and dissimilar friction stir welded AA 5182-H111 and AA 6016-T4 tailored blanks, Materials \& Design 30 (2009), No. 8, pp. 3235-3242, 2009 DOI:10.1016/j.matdes.2008.12.005

$11 \mathrm{~J} . \mathrm{Li}$ : The effect of weld design on the formability of laser tailor welded blanks, Master thesis, University of Waterloo, 2010

12 J. Li, SS. Nayak, E. Biro, SK. Panda, F. Goodwin, Y. Zhou: Effects of weld line position and geometry on the formability of laser welded high strength low alloy and dual-phase steel blanks, Materials \& Design 52 (2013), pp. 757-766 DOI:10.1016/j.matdes.2013.06.021

13 M. Parente, R. Safdarian, A. D. Santos, A. Loureiro, P. Vilaca, R. M. Natal Jorge: A study on the formability of aluminum tailor welded blanks produced by friction stir welding, International Journal of Advanced Manufacturing Technology 83 (2016), No. 9-12 DOI:10.1007/s00170-015-7950-0

14 E. Knabe: Ziehen von Blechformteilen aus zusammengeschweißten Platinen unterschiedlicher Blechdicke und Güte ("Tailored Blanks"). Dissertation, Universität Stuttgart, 1997

15 B. L. Kinsey; X. Wu: Tailor Welded Blanks for Advanced Manufacturing, Woodhead, Cambridgeshire, UK, 2011

16 J. Cao, B. Kinsey: Adaptive method and apparatus for forming tailor welded blanks, U.S Patent No 5,941,110, 1999

17 T. Mennecart, H. Hassan, A. Güner, N. Ben Khalifa, M. Hosseini: Deep drawing of highstrength tailored blanks by using tailored tools, Materials, vol. 9, no. 2, 2016 DOI:10.3390/ma9020077

18 L. C. Chan, S. M. Chan, T. C. Lee: Tailor-welded blanks of different thickness ratios effects on 
forming limit diagrams. Journal of Materials Processing Technology 132 (2003), No. 1-3 DOI:10.1016/S0924-0136(02)00407-7

19 P. J. Ramalu, R. G. Narayanan, S. V. Kailas: Forming limit investigation of friction stir welded sheets: influence of shoulder diameter and plunge depth, The International Journal of Advanced Manufacturing Technology 69 (2013) DOI:10.1007/s00170-013-5245-x

20 M. Werz, S. Weihe: Verfahren zum Rührreibverschweißen sowie rührreibverschweißtes Werkstück, DE 102015112 416.5A, 2015

$21 \mathrm{~J}$. Liu: Novelis aluminium new progresses in auto BiW lightweight applications, 2012 Automotive International Congress, 2012

22 DIN EN 10346: Kontinuierlich schmelztauchveredelte Flacherzeugnisse aus Stahl zum Kaltumformen -Technische Lieferbedingungen; Deutsche Fassung EN 10346:2015

23 The Aluminum Association: International alloy designations and chemical composition limits for wrought aluminum and wrought aluminum alloys, 2015

24 DIN EN ISO 6892-1: Metallische Werkstoffe Zugversuch - Teil 1: Prüfverfahren bei Raumtemperatur, 2017

25 V. V. Hasek: Untersuchung und theoretische Beschreibung wichtiger Einflussgrößen auf das Grenzformänderungsschaubild, Blech Rohre Profile 25 (1978), pp. 213-220, 285-292, 493-499, 613-627

26 F. Panzer, M. Werz, P. L. Nguyen, M. Schneider, S. Weihe, M. Liewald: Ressourcenschonende Mischschweißverbindungen für Hochleistungs-Leichtbauverbunde. Abschlussbericht, Universität Stuttgart, 2018

27 DIN EN ISO 12004-2: Metallische Werkstoffe Bleche und Bänder - Bestimmung der Grenzformänderungskurve - Teil 2: Bestimmung von Grenzformänderungskurven im Labor
(ISO 12004-2:2008); Deutsche Fassung EN ISO 12004-2:2008

\section{Bibliography}

DOI 10.3139/120.111366

Materials Testing

61 (2019) 7, pages 643-651

(c) Carl Hanser Verlag GmbH \& Co. KG

ISSN 0025-5300

\section{The authors of this contribution}

Florian Panzer joined the Materials Testing Institute (MPA) University of Stuttgart in 2018 as a research assistant in the unit "Welding and Joining Technology”. After receiving his Master's degree in Mechanical Engineering from the University of Stuttgart in 2016, he started to work as a research assistant at the Institute for Materials Testing, Materials Science and Strength of Materials (IMWF) of the University of Stuttgart, Germany. The focus of his current work is on the joining of dissimilar materials with friction stir welding, as well as on the experimental and numerical investigation of the dynamics of the friction stir welding process.

Matthias Schneider studied Mechanical Engineering (Dipl.-Ing.) at Friedrich-Alexander-University in Erlangen-Nürnberg. His majors were Production Engineering and Plastics Technology. He joined the University of Stuttgart, Germany in 2013 and since then has been working in the field of sheet metal forming. His principal task is the development of new sheet metal forming tools and technologies.

Dipl.-Ing. Martin Werz joined the Materials Testing Institute (MPA) University of Stuttgart in 2016, as Head of the "Welding and Joining Technology" unit. Since 2017, he has been Head of the
Department "Joining Technology and Additive Manufacturing”. In 2011, he earned his Master's degree at George Washington University in Washington, DC, USA, on the topic "Transportation Safety Engineering”. In 2012, he completed his degree (Dipl.-Ing.) in the field of Mechanical Engineering and started to work as an academic staff member at the Institute for Materials Testing, Materials Science and Strength of Materials (IMWF) of the University of Stuttgart, Germany. In 2016, he obtained a degree as welding engineer. He regularly participates in ScienceSlams, where scientists present their research work in front of a non-expert audience, and won the German ScienceSlam Championships in 2017 with his slam title "Friction Stir Welding in the Kitchen" ("Rührreibschweißen in der Küche"). He shows great interest in the correlations between process parameters, material properties and the resulting joint strength. Aside from experimental process studies and optimizations, he is engaged in the continuum mechanical modeling and simulation of the friction stir welding process.

Prof. Dr. Stefan Weihe has been Director of the Materials Testing Institute (MPA) University of Stuttgart as well as Head and Full Professor of the Institute of Materials Testing, Materials Science and Strength of Materials (IMWF) of the University of Stuttgart, Germany, since 08/2014. He received his doctorate in Aerospace Engineering at the Institute for Statics and Dynamics of Aerospace Structures, University of Stuttgart in 1998 and afterwards began working as a Senior Expert for Chassis Strength, Friction and Wear for Audi AG, Ingolstadt, Germany. From 2002 to 2014, he was a Senior Manager in the field of Strength and Fatigue, Body in White, and Body Concepts and Advanced Engineering in the Development \& Research Department, Division Mercedes-Benz Vans, Daimler AG, Stuttgart, Germany. 